\title{
Ciliated Cell Variant of Endometrial Carcinoma in an Adenomyoma in Uterus
}

\author{
Sameera Rashid ${ }^{1}$, Mohammed Akhtar ${ }^{1}$ \\ 1. Laboratory Medicine and Pathology, Hamad Medical Corporation, Doha, QAT \\ Corresponding author: Sameera Rashid, sameera.m831@gmail.com
}

\begin{abstract}
Ciliated cell variant of endometrioid adenocarcinoma (CCVEA) is an extremely rare tumor that has been seldom reported in the literature as low-grade endometrioid carcinoma with a favorable prognosis. CCVEA is characterized by neoplastic glands composed predominantly of ciliated cells with relatively little nuclear atypia. Recognition of the ciliated component is the key to the diagnosis of CCVEA but it can lead to diagnostic confusion with tubal metaplasia especially on endometrial biopsies. Herein, we report the case of a 56 -year-old woman who presented with post-menopausal vaginal bleeding. Endometrial biopsy revealed extensive atypical complex endometrial hyperplasia composed predominantly of ciliated cells. The patient subsequently had a hysterectomy and bilateral salpingo-oophorectomy that revealed a large adenomyoma, adherent to the right ovary. The adenomyoma was extensively involved by CCVEA with some extension to the endometrial cavity. To the best of our knowledge, this is the first report of CCVEA that appears to arise in an adenomyoma.
\end{abstract}

Review began 06/14/2021 Review ended 06/27/2021 Published 07/03/2021

๑) Copyright 2021

Rashid et al. This is an open access article distributed under the terms of the Creative Commons Attribution License CC-BY 4.0., which permits unrestricted use, distribution, and reproduction in any medium, provided the original author and source are credited.
Categories: Obstetrics/Gynecology, Oncology

Keywords: ciliated cell variant of endometrioid adenocarcinoma, low grade endometrial carcinoma, tubal metaplasia, cilia, endometrial carcinoma

\section{Introduction}

Ciliated cells in the endometrium are usually seen in benign lesions especially in tubal metaplasia [1]. Scattered ciliated cells may be seen in endometrial adenocarcinoma. However, endometrial carcinomas composed predominantly of the ciliated cell are rare [2]. To date, 15 cases of ciliated cell variant of endometrial adenocarcinoma (CCVEA) have been reported in the literature [2-7]. However, in all these cases the carcinoma was arising in the endometrium. We encountered a post-menopausal female with ciliated endometrial carcinoma mainly involving a uterine adenomyoma. To the best of our knowledge, this is the first case of CCVEA with possible origin in an adenomyoma.

\section{Case Presentation}

A 56-year-old female, multipara, eight years post-menopausal, presented with multiple episodes of vaginal bleeding. On clinical examination, the uterus appeared bulky without palpable adnexa. The uterine ultrasound showed endometrial thickening suggestive of hyperplasia (Figure 1). 


\section{Cureus}



FIGURE 1: Ultrasound of the uterus showing increased endometrial thickness in the area marked by asterisks.

Hysteroscopy showed first-degree uterine prolapse and an endometrial polyp. Endometrial biopsy revealed extensive atypical complex endometrial hyperplasia composed predominantly of ciliated cells and carcinoma could not be ruled out. Hysterectomy and bilateral salpingo-oophorectomy were performed that grossly showed endometrial cavity expanded by thick friable material interspersed with areas of necrosis. Histologically, the endometrium was necrotic with complex atypical hyperplasia and a focal ciliated variant of endometroid carcinoma (Figure 2). The uterus also contained a solid $4 \mathrm{~cm} \times 2 \mathrm{~cm} \times 1.5 \mathrm{~cm}$ grayish tan spongy mass projecting from the uterine surface and adherent to the right ovary. This mass was composed of well-differentiated smooth muscle cells along with intricate glandular components composed of prominently ciliated cells (Figure 3). In several areas, back-to-back glands were identified with nuclear atypia indicating carcinomatous growth (Figure 4). The right ovary was free of tumor and all margins were negative. The patient was treated with adjuvant chemotherapy and radiotherapy sandwich protocol. The patient was disease-free at the time of last follow-up i.e., two years after the surgery. 


\section{Cureus}

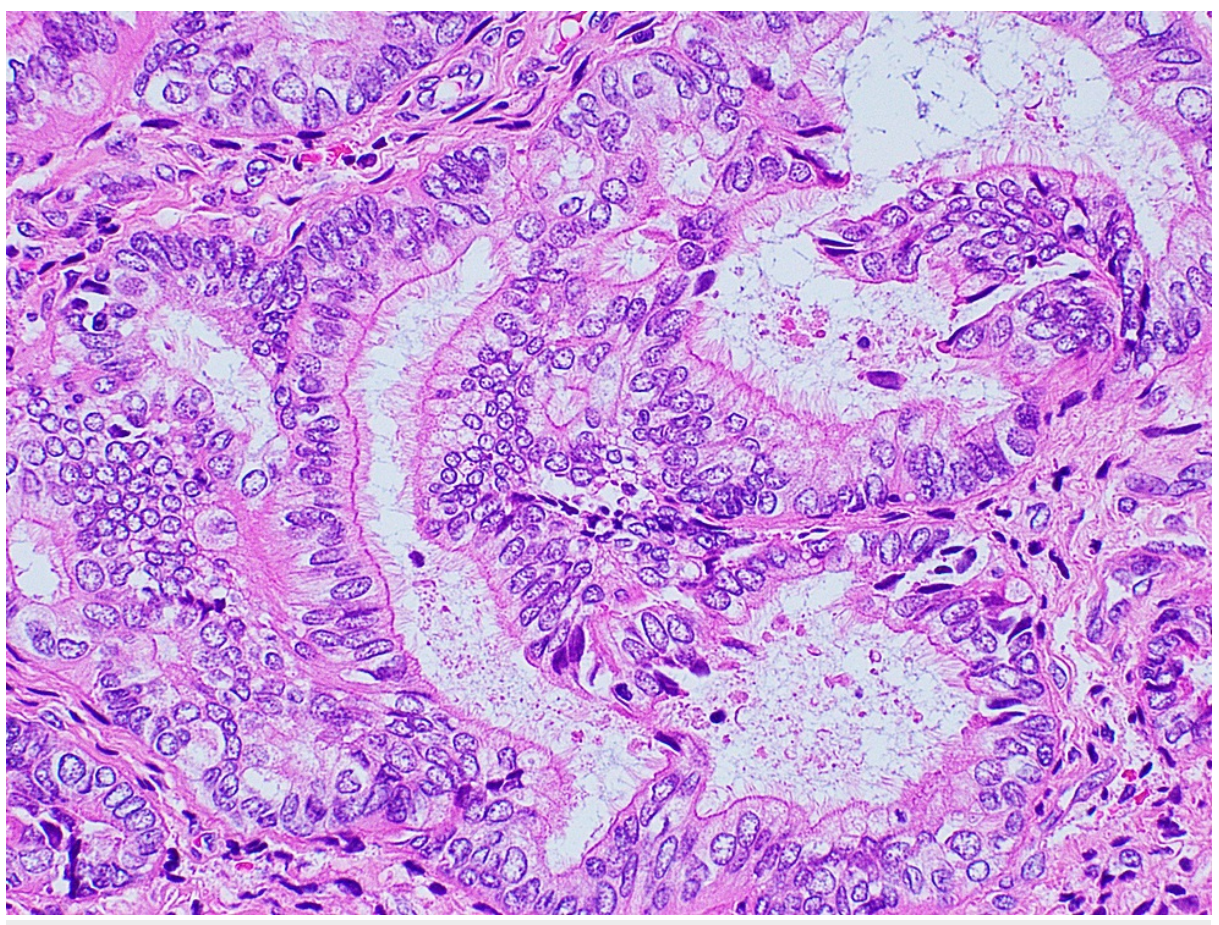

FIGURE 2: Well-differentiated endometrial adenocarcinoma showing abundant cilia.

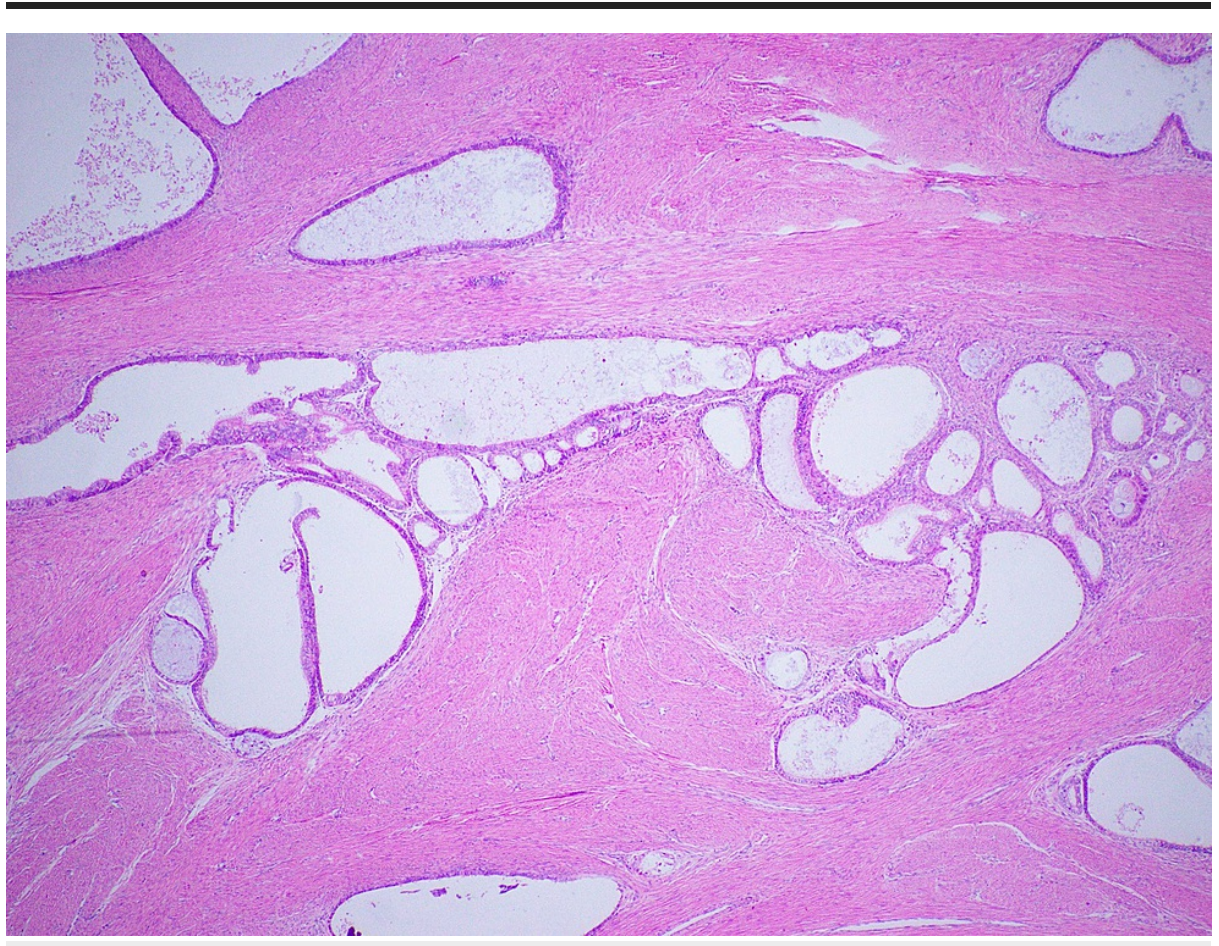

FIGURE 3: Adenomyoma with dilated endometrial glands. 


\section{Cureus}

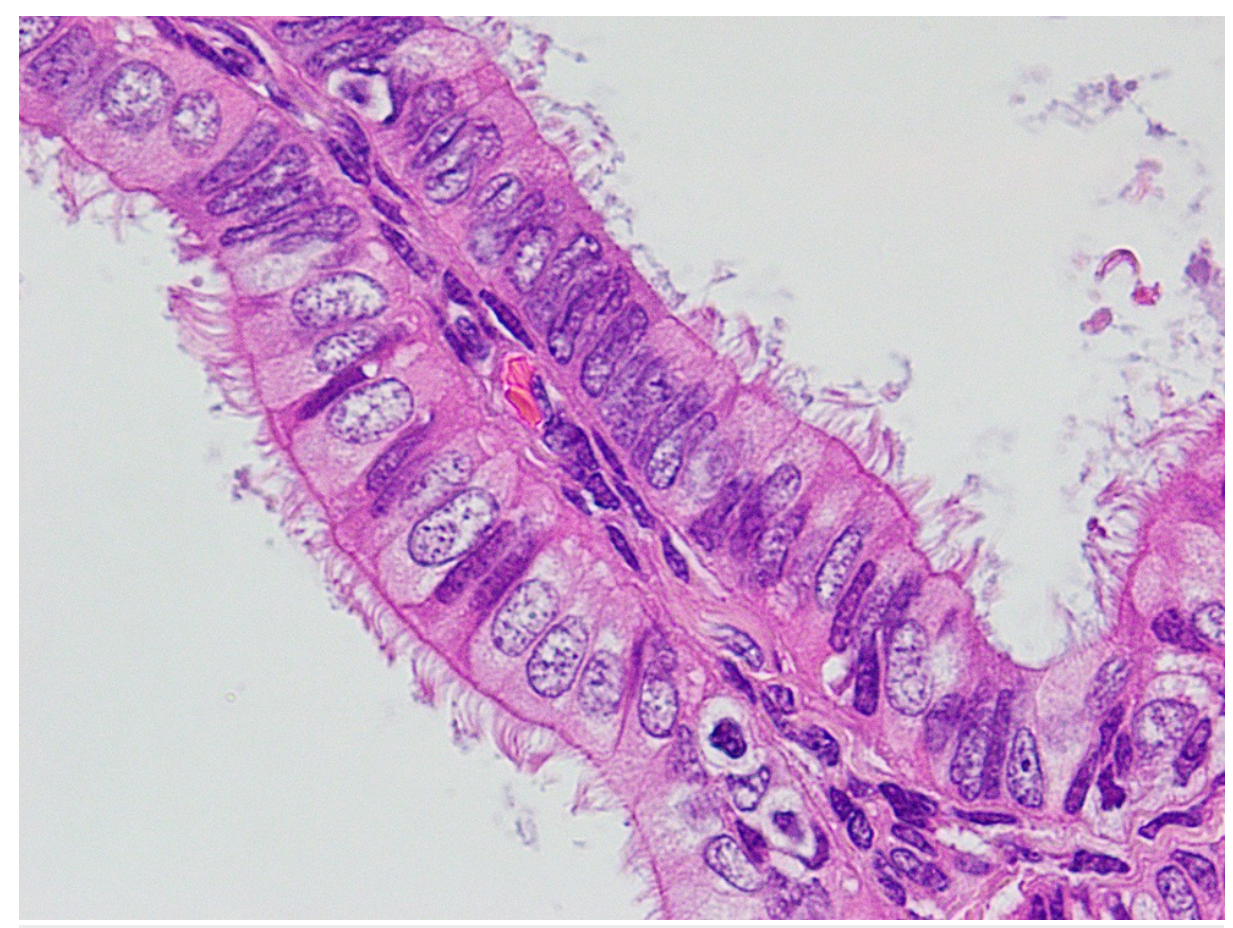

FIGURE 4: Back-to-back endometrial glands showing diffuse ciliation.

\section{Discussion}

Cilia are specialized structures associated with the epithelium of various tissues. Found in some form in all eukaryotes, these perform motility and sensory functions. Cilia are broadly divided into two types, motile and non-motile. The motile cilia are found in the lungs, respiratory tract, and middle ear. The non-motile or primary cilia play a significant role in the kidney and photoreceptors of the retina [8]. Cilia are composed of a microtubular skeleton that is surrounded by a plasma membrane. The motile cilia have a $(9+2)$ structure with nine pairs of microtubules and a central pair as well. The primary cilia have a $(9+0)$ structure meaning nine pairs of microtubules without any central pair. The microtubules are attached to the basal body within the cell cytoplasm [8]. Various stains can be used to identify the basal body in cilia including phosphotungstic acid-hematoxylin (PTAH) which is a variant of the trichrome stain. It also stains intracytoplasmic filaments in muscle and glial cells [9].

In many organs when adenocarcinomas arise from ciliated epithelia, the cells lose this feature of differentiation [10]. Most reported examples of ciliated adenocarcinomas are low-grade pancreatic ductal carcinoma, bronchoalveolar cell carcinoma of the lung, and borderline neoplasms of the ovary [11-13].

The Mullerian duct derivatives, cervix, endometrium, and fallopian tubes, normally contain cilia. In the endometrium, cilia are usually associated with follicular phase, anovulatory cycles, or benign proliferations like tubal metaplasia [14-15]. However, rare cases of ciliated cell variant of endometrial carcinoma have been described.

In 1983, for the first time, 10 cases of the ciliated variant of endometrial adenocarcinoma were described by Hendrickson and Kempson [2]. They did a retrospective study of 400 cases of endometrial carcinoma and 10 cases of adenocarcinoma with predominant ciliated cells (more than 75\%) were identified. All these cases were of post-menopausal women, four out of 10 above were above 70 years of age and all were confined to the uterus. All 10 of the resected uteri contained residual ciliated adenocarcinoma (after biopsy), and in five cases, ciliated carcinoma invaded the myometrium. A microscopic focus of endometrioid carcinoma, thought to be a second simultaneous primary neoplasm, was present in the ovary of one of the patients.

From then on, a couple of more cases have also been reported, mostly in post-menopausal women with lowstage disease [3-7]. Hence, overall this is regarded to have a good prognosis.

There has also been a report of a case of moderately differentiated ciliated endometrioid adenocarcinoma of the endometrium (CCVEA), diagnosed by endometrial brush cytology and confirmed by histologic examination of a simultaneously obtained hysterectomy specimen [3].

Adenomyosis is a benign condition characterized by the presence of benign endometrial glands in the myometrium. Adenocarcinoma arising from adenomyoma is rare. There have been reports of endometrial 
carcinomas arising from adenomyoma [16] and a few reports of tumors arising from adenomyosis [17-18]. However, none of these were reported to be the ciliated variant of endometrial carcinoma. Adenomyosis may present as a polypoid and is termed polypoid adenomyoma. Atypical polypoid adenomyomas are rare lesions characterized by biphasic proliferation of complex and atypical endometrial glands within a myofibromatous stroma. Their significance lies in an increased risk of recurrence and rarely, malignant transformation into endometrioid adenocarcinoma [19]. None of these have been reported to manifest ciliated epithelium. Malignant lesions arising from adenomyoma post a higher threat of being disregarded as a fibroid/benign lesion preoperatively based on imaging studies [20].

\section{Conclusions}

Ciliated cells in an endometrial sample are usually attributed to tubal metaplasia. However, they may be a component of the CCVEA. CCVEA is an extremely rare tumor that has been sporadically reported as a lowgrade endometrioid carcinoma with a favorable prognosis. The present case, however, is a CCVEA probably arising in an adenomyoma. This report is a reminder that ciliated cells within atypical glands may represent CCVEA with malignant behavior and has the potential to metastasize. Hence, ciliated endometrium, especially in a post-menopausal woman, should be assessed with caution. Tubal metaplasia being the most common, should not impede us from looking for ciliated carcinoma.

\section{Additional Information}

\section{Disclosures}

Human subjects: Consent was obtained or waived by all participants in this study. Medical Research Center, Hamad Medical Corporation, Qatar issued approval MRC-04-20-1082. The Medical Research Center has granted permission for this case report to be published on the condition that no patient-identifiable data (including patient name and photograph) are included. . Conflicts of interest: In compliance with the ICMJE uniform disclosure form, all authors declare the following: Payment/services info: All authors have declared that no financial support was received from any organization for the submitted work. Financial relationships: All authors have declared that they have no financial relationships at present or within the previous three years with any organizations that might have an interest in the submitted work. Other relationships: All authors have declared that there are no other relationships or activities that could appear to have influenced the submitted work.

\section{References}

1. Hendrickson MR, Kempson RL: Uterus and fallopian tubes. Histology for Pathologists. Sternberg SS (ed): Lippincott-Raven, Philadelphia; 1991. 4:797-834.

2. Hendrickson MR, Kempson RL: Ciliated carcinoma--a variant of endometrial adenocarcinoma: a report of 10 cases. Int J Gynecol Pathol. 1983, 2:1-12. 10.1097/00004347-198301000-00001

3. Maksem JA: Ciliated cell adenocarcinoma of the endometrium diagnosed by endometrial brush cytology and confirmed by hysterectomy: a case report detailing a highly efficient cytology collection and processing technique. Diagn Cytopathol. 1997, 16:78-82. 10.1002/(SICI)1097-0339(199701)16:1<78::AIDDC17>3.0.CO;2-8

4. Low S, Nicol A: Ciliated cell variant of endometrioid adenocarcinoma: a rare tumour . J Clin Pathol. 2004, 57:1341-1342.

5. Haibach H, Oxenhandler RW, Luger AM: Ciliated adenocarcinoma of the endometrium. Acta Obstet Gynecol Scand. 1985, 64:457-462. 10.3109/00016348509155168

6. Gould PR, Li L, Henderson DW, Barter RA, Papadimitriou JM: Cilia and ciliogenesis in endometrial adenocarcinomas. An ultrastructural analysis. Arch Pathol Lab Med. 1986, 110:326-330.

7. Motoyama T, Ajioka Y, Ohta T, Watanabe H: Ciliated carcinoma of the endometrium associated with mucinous and neuroendocrine differentiation: a case report with immunohistochemical and ultrastructural study. Pathol Int. 1994, 44:480-485. 10.1111/j.1440-1827.1994.tb01714.x

8. Mirvis M, Stearns T, James Nelson W: Cilium structure, assembly, and disassembly regulated by the cytoskeleton. Biochem J. 2018, 475:2329-2353. 10.1042/BCJ20170453

9. Dey P: Chapter 10, Connective tissue stain: principle and procedure . Basic and Advanced Laboratory Techniques in Histopathology and Cytology. Springer, Singapore; 2018. 106-107. 10.1007/978-981-10-8252$8 \_10$

10. Hidvegi DF, Gurley AM: Electron microscopy. Comprehensive Cytopathology. Bibbo M (ed): WB Saunders, Philadelphia; 1991. 917-945.

11. Liebow AA: Bronchoalveolar carcinoma. Adv Int Med. 1960, 10:329-358.

12. Scully RE: Tumors of the Ovary and Maldeveloped Gonads . Armed Forces Institute of Pathology, Washington DC; 1979.

13. Sommers SC, Meissner WA: Unusual carcinomas of the pancreas. Arch Pathol. 1954, 58:101-111.

14. Silverberg SG: Problems in the differential diagnosis of endometrial hyperplasia and carcinoma . Mod Pathol. 2000, 13:309-327. 10.1038/modpathol.3880053

15. Masterton R, Armstrong EM, More IA: The cyclical variation in the percentage of ciliated cells in the normal human endometrium. J Reprod Fertil. 1975, 42:537-540. 10.1530/jrf.0.0420537

16. Antovska VS, Krstevska I, Trajanova M, et al.: Endometrioid adenocarcinoma arising in adenomyoma in a woman with a genital prolapse - case report. Open Access Maced J Med Sci. 2018, 14:1091-1094.

17. Mori M, Furusawa A, Kino N, Uno M, Ozaki Y, Yasugi T: Rare case of endometrioid adenocarcinoma arising from cystic adenomyosis. J Obstet Gynaecol Res. 2015, 41:324-328. 10.1111/jog.12513 


\section{Cureus}

18. Sasaki T, Sugiyama T, Nanjo H, et al.: Endometrioid adenocarcinoma arising from adenomyosis: report and immunohistochemical analysis of an unusual case. Pathol Int. 2001, 51:308-313. 10.1046/j.14401827.2001.01200.x

19. Inoue $\mathrm{K}$, Tsubamoto $\mathrm{H}$, Hori M, Ogasawara T, Takemura T: A case of endometrioid adenocarcinoma developing 8 years after conservative management for atypical polypoid adenomyoma. Gynecol Oncol Case Rep. 2014, 8:21-23. 10.1016/j.gynor.2014.02.001

20. Heo SH, Lee KH, Kim JW, Jeong YY: Unusual manifestation of endometrioid adenocarcinoma arising from subserosal cystic adenomyosis of the uterus: emphasis on MRI and positron emission tomography CT findings. Br J Radiol. 2011, 84:e210-e212. 10.1259/bjr/24318075 